\title{
Research flourishes, even in harsh climate
}

DESPITE its recent political isolation and limited funding for research, South Africa has managed to maintain a world-class scientific tradition in several disciplines. Bibliometric and citation-based surveys tend to confirm the view in the scientific community that the country is particularly strong in four fields: organismic biology, Earth sciences, astronomy and clinical medicine.

The topics are not surprising, given the country's situation and its natural environment. South Africa has remarkable biodiversity, and an interesting geological history, which have provided the focus of botanical, zoological and geological studies. And its excellent viewing conditions have made it the focus of southern hemisphere astronomy since Herschel first visited the Cape in the 1830s.

In addition, a national shortage of water has prompted research on water resources, while the importance of the mining industry ensures that metallurgy is well supported. Finally, the existence of world-class medical facilities has enabled South African clinicians to make greater advances than elsewhere in the continent.

But there remain significant disparities between the distribution of South Africa's research budget (see table, opposite page) and the disciplines in which the country has demonstrable scientific strength. Apart from the activities of the Atomic Energy Corporation, for example, the country's most important civilian capital project has been a $200-\mathrm{MeV}$ cyclotron, opened 11 years ago at the National Accelerator Centre at Faure, $30 \mathrm{~km}$ east of Cape Town.

This is not a scientific field in which South Africa enjoys a particularly high international reputation. Yet recent cutbacks experienced by most research and tertiary institutions appear not to have applied to the accelerator centre. Its staff has increased by 10 per cent over the past two years, and its budget has risen by $\mathrm{R} 3$ million to R38 million.

The centre's new director, John SharpeyShaffer, who took up office a year ago, concedes that it is a bigger institution than one would expect to find in South Africa. "There are people who don't like it, and they have a good case," he says. The centre is currently being reviewed by a panel of experts including three foreign and two local members. Sharpey-Shaffer thinks that its future lies not as a privatized medical facility, but in heavy-ion research, and has spent R4.5 million so far in developing gamma-ray detectors for this purpose.

Astronomy has a better case for being treated as a legitimate 'big science'. The South African Astronomical Observatory (SAAO) has recently revised its plans for a new Southern African Large Telescope to replace the existing 1.9-metre telescope at

\section{IMAGE UNAVAILABLE FOR COPYRIGHT REASONS} The King Protea is part of South Africa's rich
biodiversity, a key factor of its science.

its observatory at Sutherland, about $400 \mathrm{~km}$ north-east of Cape Town. The original proposal was for a 4-metre class telescope using modern thin-mirror technology with active and adaptive optics (see Nature 372, 394; 1994).

Last month SAAO announced that it is now seeking an 11-metre spectroscopic survey telescope, similar to the HobbyEberly Telescope (HET) nearing completion at the MacDonald Observatory in Texas. Case Rijsdijk, the SAAO's education officer, says that this could be produced at
3 an estimated cost of R90 million, two-thirds of the price of the 4-metre telescope originally proposed, as the hexagonal mirror comprises an array of 91 lightweight mirrors, which are relatively inexpensive to produce.

The design provides 70 per cent sky coverage, while keeping constant gravity's pull on the mirrors, so avoiding distortions that can compromise image quality. Moreover, it would not be overshadowed by other larger telescopes in the southern hemisphere, chiefly the new European Southern Observatory telescope under construction at Paranal in Chile.

The new instrument would provide a complementary facility for the HET in the southern hemisphere. According to Rijsdijk, it would enable South Africa to retain its important position in world astronomical research.

The SAAO plans to construct the telescope at its observatory at Sutherland. It abandoned the idea of being involved in the development of the Gamsberg site, in Namibia, after the government indicated that it would be unwilling to invest in a site outside South Africa's borders.

Whether the government will be prepared to look more favourably at the new plan remains to be seen. But Lionel Mtshali, the new minister for arts, culture, science and technology, has assured his support for the project, which he regards as "an exciting development". The SAAO is asking the government for R10 million a year for the next five years, and hopes to raise the balance from foreign funding sources.

\section{All change for university funding?}

SoUTH African universities appear to be entering a new period of uncertainty, following the publication last month of the final report of the National Commission for Higher Education, which proposes farreaching changes in the financing of tertiary education and is likely to become the basis of government policy.

The report suggests how future growth in student numbers might be kept in line with the country's manpower requirements. Many agree that this will help to make up for the current poor correlation between the universities' graduate output and national needs. But critics point out that the report does not even promise to maintain existing levels of research funding for universities.

The commission has been chaired by Jairam Reddy, a former rector of the University of Durban-Westville. It proposes that in future the state should finance the research and teaching components of a university's subsidy separately, so that outputs from both can be accounted for independently. But it makes no specific pro-

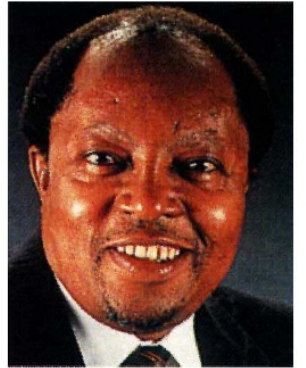

Bengu: 'universities must be accountable'. cellor of the University of Fort Hare argues that his department is "committed to upgrading the research capacity of universities", and promises that incentives aimed at doing this will be incorporated in the new funding formula.

The government is currently preparing a response to the commission's report. Bengu says that a white paper will be published within the next few months, and that legislation will be put before parliament by next May. If it is approved, universities will be 